\title{
A CONFUSÃo de COMPETÊNCIAS ENTRE AS ESFERAS JURÍdicA E POLÍTICA NO PROCESSO DE IMPEACHMENT 1
}

Stephanie Barone Erhardt2, Tatyana Léllis da Matta e Silva3.

\begin{abstract}
RESUMO
O presente artigo tem como finalidade discutir sobre o processo de impeachment, mais especificamente sobre a atuação e competência das esferas Jurídica e Política durante esse processo. Trata-se de um processo político-administrativo decorrente do exercício de uma função pública. O impeachment possui conteúdo inteiramente político assim como sanções basicamente políticas. Porém, é regido por lei especial e ocorre dentro dos moldes jurídicos. Para tanto, buscou-se esclarecer sobre a história das Constituições anteriores e o processo de formação do sistema de governo presidencialista, afim de facilitar a compreensão sobre o procedimento em pauta, e explanar a respeito da ADPF 378, para, a partir de então, abranger sobre o principal objetivo a ser discutido, embasando a real função de cada esfera durante o processo de Impeachment.
\end{abstract}

Palavras-chave: Direito Constitucional - Impeachment - Presidencialismo de Coalizão - Separação de Poderes.

\section{INTRODUÇÃO}

Abordaremos no presente artigo a respeito do processo de impeachment, mais especificamente no que tange a divisão de competências entre os poderes nesse processo, assim como a confusão entre o âmbito político e jurídico existente nesse cenário.

Partindo do histórico das Constituições, será apresentado, de forma sucinta, como se deu a atual forma de governo, a divisão dos poderes e a organização governamental. Desta forma, será mais detalhado o estudo a respeito do sistema presidencialista, em que o Presidente da República figura como peça central dessa estrutura e cumula a função de Chefe de Governo e Chefe de Estado. Assim como o presidencialismo de coalizão, sistema adotado atualmente no Brasil, marcado pela característica comum do presidencialismo com união da coalizão partidária.

Importante mencionar desde de já, que no presidencialismo, adota-se a divisão tripartite de poder, baseado na teoria de Montesquieu, com a existência da esfera Executiva, Legislativa e Judiciária, sustentada no sistema de freios e contrapesos, de forma que os poderes são independentes e autônomos, e atuam como seus próprios fiscalizadores.

\footnotetext{
1 Trabalho de conclusão de curso de Direito de 2016 pela MULTIVIX - Vitória, orientado pela Professora, Advogada e Mestre Tatyana Léllis da Matta e Silva.

2 Acadêmica do curso de Direito da Faculdade Multivix.

3 Advogada e Mestre em Ciências Sociais pela UFES.
} 
Aqui, há a existência de uma forte influência do sistema norte americano de governo, conhecido como "judicial review of legislation", baseado no controle difuso de Constitucionalidade, em que a Constituição é constantemente fiscalizada, não só por um único órgão.

Seguimos para a descrição do processo de impeachment, acompanhado de suas normas e procedimentos. Trata-se de um processo político utilizado para processar e julgar os crimes de responsabilidade praticados pelo Presidente da República, respeitando os moldes jurídicos de processo. Inicia-se a partir de então, o objeto central do presente artigo, a discussão da confusão entre o âmbito político e jurídico.

Neste ponto, vale considerar a teoria da Constituição apresentada por Carl Schmitt, onde o limite entre a política e o direito apresenta-se de forma indeterminada. Assim, Schmitt traz em sua obra "O guardião da Constituição", duas esferas distintas, mas extremamente interligadas, na medida em que a Constituição é a formalização do direito, que provém, além marco histórico, das decisões políticas.

Nesse contexto é definido:

A constituição não é algo que se dá a si mesma, como uma autorização ao seu existir, mas algo que é dado por unidade política concreta e efetiva (SCHMITT, 2008, p. 46).

No fundo de toda normatividade reside uma decisão política do titular do poder constituinte, (SCHMITT, 2008, p. 47).

Assim, é explicito que o cenário em questão é bastante conflituoso, o que é agravado no processo de impedimento se levarmos em consideração o sistema de governo vigente no país. É nesse sentido que será apresentado, dentro do contexto, a ADPF 378, as alterações por ela ocasionadas assim como a análise mais específica do tema, abarcando a instável e delicada estruturação dos Poderes Legislativos, Executivo e Judiciário, suas respectivas competências assim como o risco ocasionado a eficácia desses poderes quando ocorre a construção de alianças e acordos entre as esferas Executiva e Legislativa.

\section{HISTÓRICO DAS CONSTITUIÇÕES BRASILEIRA (1824-1988)}

\subsection{A Constituição de 1824}

A primeira Constituição Brasileira, a Constituição Política do Império do Brasil, também conhecida como Carta Imperial, foi outorgada por D. Pedro I em 1824. Marcada pela forma monárquica de governo, pautada na ideia de que o poder emanava de um direito divino destinado a uma determinada pessoa ou a uma família específica, institui-se a formulação quadripartite de poder: Poder Legislativo, Poder Executivo, Poder Judiciário e Poder Moderador.

Assim, as antigas capitanias, foram divididas em províncias. E o catolicismo foi definido como religião oficial do Império, de forma que só poderiam ser eleitos para cargos oficiais os católicos apostólicos romanos.

A respeito do Poder Moderador, este era exercido privativamente pelo Imperador, que atuava como chefe supremo da Nação e buscava a manutenção da independência, o equilíbrio, e a 
harmonia dos demais poderes políticos. O Poder Executivo, exercido pelos Ministros de Estado também tinha o Imperador como chefe. Já o Poder Judiciário era composto de juízes e jurados e o Poder Legislativo formado por Deputados e Senadores, sendo aqueles eletivos e temporários e estes, nomeados pelo Imperador para atuarem vitaliciamente. Vale constar que o voto era indireto e censitário. Neste molde, foi instituída uma forma unitária de Estado com forte centralização político-administrativa.

\subsection{A Constituição de 1891}

Em 1891 foi promulgada a Constituição da República dos Estados Unidos do Brasil, onde adotou-se a República como forma de governo.

As antigas províncias deram origem aos Estados-membros e o antigo Município neutro ao Distrito Federal. Desta forma nasceu o Estado federal Brasileiro. A partir de então, adotou-se a formulação tripartite de poder: Poder Legislativo, Executivo e Judiciário, que atuavam de forma harmônica e independentes entre si. Passando não mais a existir o poder moderador. Além disso, o presidencialismo foi estabelecido como regime de governo, em que, a partir do voto direto do povo era eleito o Presidente da República. Abolindo-se, consequentemente, o sistema parlamentarista.

Vale constar também que, na Constituição de 1891 houve ampliação da declaração de direitos humanos. Essa nova fase, representava um marco na história do Brasil, pois dava início a uma nova forma de governo.

\subsection{A Constituição de 1934}

A Constituição de 1934 manteve os moldes básicos da Constituição anterior: a República, a Federação, a tripartição de poderes, o Presidencialismo e o regime representativo. Houve a ampliação dos Poderes do Executivo, a criação de alguns direitos trabalhistas, além da definição de direitos políticos e eleitorais. O Voto passou a ser secreto e se estender também as mulheres. Além disso, ocorreu a integração da Justiça Militar e da Justiça Eleitoral como órgãos do Poder judiciário.

\subsection{A Constituição de 1937}

A Constituição outorgada por Getúlio Vargas em 1937, foi inspirada na Constituição Fascista da Polônia, e por isso, recebeu o apelido de "Polaca".

Houve o fortalecimento do Poder Executivo Federal, de forma que o Presidente da República atuava tanto no Poder Executivo quanto no Poder Legislativo. Assim o Brasil passou a ser um Estado Federal apenas formalmente, pois com acúmulo de competências concentradas na mão do Presidente da República as unidades federativas comprometiam sua autonomia e capacidade política (característica fundamental na forma de Estado Federal). 


\subsection{A Constituição de 1946}

A Constituição de 1946 restaurou a autonomia das entidades federadas e fortaleceu o regime democrático, criando novamente o cargo de Vice-presidente da República (extinto em constituições passadas), assegurando, o pluripartidarismo. Nesta esteira, importante relatar que, durante o período de 1961 a 1963 houve a reintrodução do regime parlamentarista no Brasil, interrompendo o ciclo do Regime Republicano instaurado.

\subsection{A Constituição de 1967}

A Constituição de 1967 foi promulgada quando assumia a Presidência da República o Marechal Arthur da Costa e Silva. Esta preocupou-se principalmente com a segurança nacional. Houve a centralização dos poderes no Executivo Federal, além da redução da autonomia individual, permitindo a suspensão dos direitos e garantias constitucionais. Houve também, a criação das eleições indiretas para presidente da República (colégio eleitoral).

\subsection{A Constituição de 1969}

Como Emenda Constitucional 1 à Constituição de 1967, a Constituição da República Federativa do Brasil passou a vigorar em 1969. Entretanto, esta Constituição só se apresentou como emenda no plano teórico, uma vez que foi promulgado um texto totalmente reformulado, e, em se tratando de emenda Constitucional deve se alterar apenas uma parte da Constituição e não a integralidade de seus dispositivos. Portanto, a doutrina majoritária entende que não se trata de uma emenda e sim de uma nova Constituição (art 34 do ADCT da CF/1988).

No que tange ao conteúdo, buscou-se a centralização do Poder Político nas mãos do Executivo Federal, assim como na Constituição anterior.

\subsection{A Constituição de 1988}

A Constituição da República Federativa do Brasil promulgada em 1988, também chamada de Constituição "Cidadã".

Nesta fase, houve a instituição do Estado Democrático de Direito, limitando o Poder do Estado ao cumprimento da lei. Ademais, foi assegurado a livre participação dos cidadãos na vida política. Assim, o voto passou a ser universal, direto e secreto nas três esferas administrativas, além disso, os analfabetos passaram a ter direito a voto, assim como foi facultado aos maiores de 16 o direito de votar. Estabeleceu-se o Pluripartidarismo e fortaleceu-se o Federalismo, conferindo maior autonomia aos entes federados. Outrossim, o presidencialismo recuperou algumas características do sistema Estadunidense de governo, com o fortalecimento do Legislativo e do Judiciário. 


\title{
2 SISTEMA PRESIDENCIALISTA E O "PRESIDENCIALISMO DE COALIZÃO" 4 NO BRASIL
}

\subsection{Sistema Presidencialista}

Conforme a história das Constituições Brasileiras acima apresentada, percebe-se que o presidencialismo vigorou quase de forma ininterrupta no Brasil. De uma forma geral, o presidencialismo está ligado ao sistema Republicano de Governo, onde prevalece a vontade popular. Marcado pela separação clássica dos poderes: Executivo, Legislativo e Judiciário (teoria tripartite de Montesquieu). Poderes estes, que atuam de forma autônoma e harmônica entre si.

Como define Russomano:

O presidencialismo, fundamentalmente, caracteriza-se pela separação de Poderes. Embasado no pensamento de Montesquieu, que aperfeiçoou a doutrina, consagrando-a em definitivo, considera os órgãos estatais tripartidos e independentes, cabendo a cada um sua função específica. (RUSSOMANO, 1997, p. 128).

Porém, outra característica marcante do presidencialismo é que, a figura do Chefe de Governo e Chefe de Estado apresenta-se de forma conjunta, ou seja, não há distinção, o presidente acumula ambas as funções. Assim sendo, fica claro afirmar que o Presidente é a peça principal do presidencialismo. Esta figura do Poder Executivo é eleita através do voto popular e exerce atividades como coordenação e execução de políticas públicas, escolha de Ministros, poder de veto em projetos de lei vindos do Legislativo, entre outros.

Sobre o tema, afirma Bastos:

\begin{abstract}
No presidencialismo, desaparece a importância do Presidente contar com a maioria no Legislativo, pois ela não constitui fator decisivo para sua manutenção no cargo: o presidente da república dispõe dos meios necessários para manter-se no cargo e executar as leis. Um bom êxito global da sua política vai depender, é certo, de um bom relacionamento com o Legislativo, único meio que the pode assegurar a realização integral da sua política, uma vez que essa sempre dependerá de leis e da aprovação de verbas que a custeie. (BASTOS, 1989, p. 89-90).
\end{abstract}

Nesta esteira, pode-se afirmar que o Presidente não precisa ter qualquer relação com o Poder Legislativo, ou seja, ele pode ser eleito para atuar no Poder Executivo sem sequer ter exercido qualquer cargo do Poder Legislativo. Através do voto, a sociedade escolhe de forma distinta seus representantes em cada esfera. Mas, é importante constar, ao mesmo tempo em que há a expressa independência entre os Poderes, ocorre também a extensa relação entre os mesmos, de forma que o equilíbrio é essencial para o bom funcionamento do sistema presidencialista.

A partir de tal afirmação pode-se abordar de forma um pouco mais específica o sistema presidencialista no Brasil, também conhecido por "Presidencialismo de Coalisão". Assim como também, discorrer sobre a dificuldade de se manter o bom funcionamento dos Poderes Executivo, Legislativo e Judiciário, respeitando sua autonomia e exercendo apenas suas respectivas funções designadas. Vicissitude esta, que ocasiona a constante invasão de atuação de uma esfera de poder, na outra.

4 Expressão criada pelo cientista político Sérgio Henrique Hudson de Abranches afim de caracterizar o modelo de governo brasileiro, no livro Presidencialismo de coalizão: o dilema institucional brasileiro. 


\subsection{Presidencialismo de "Coalizão"}

O cientista político Sérgio Henrique Abranches criou a expressão "presidencialismo de coalizão" afim de caracterizar o modelo de governo brasileiro. O presente termo, trata de um "arranjo" político-institucional que visa manter o poder de governabilidade no país através de acordos entre o Executivo e o Legislativo.

Sobre o tema, define Antônio Carlos Pojo Rego:

O presidencialismo de coalizão nada mais é do que a forma com a qual o Poder Executivo conduz a administração pública, distribuindo postos administrativos em busca de apoio político e a formação de uma maioria parlamentar. (REGO, 2015, p. 53).

No atual cenário, onde o Poder Parlamentar apresenta-se dissolvido em vários partidos políticos, a forma encontrada pelo Executivo para assegurar seu poder foi construir alianças com o Legislativo.

Desta forma, levando em consideração a definição teórica do sistema de governo presidencialista, que defende a separação expressa dos poderes, pode-se concluir que, por esse meio, o Poder Executivo não contaria mais com a sustentação de base pelo Poder Legislativo, assim, é possível afirmar neste molde (estritamente presidencialista) que, a capacidade de governo cairia significativamente, fazendo com que a aprovação de leis de interesse do governo, bem como execução de políticas públicas ficassem severamente prejudicadas.

Isto posto, a saída que o Poder Executivo encontrou para driblar esse empasse e manter sua base de sustentação no Poder Legislativo no país, foi a criação de pactos e alianças entre esses Poderes, afim de fortalecer e garantir a proteção do Executivo possibilitando assim, a prática da agenda governamental. Vale esclarecer que tal prática, entretanto, apresenta certa confinidade com o parlamentarismo, uma vez que compromete a separação de poderes autônomos e independentes entre si (característica básica do presidencialismo, como já foi acima mencionado).

Esta particularidade do sistema político brasileiro deve-se ao fato de se unir a ideia de pacto interpartidário característico do sistema parlamentarista com a eleição direta para o chefe de governo, traço típico de presidencialismo, por isso a expressão coalizão, pois abrange um cenário que traz à tona a junção dos dois sistemas políticos. Assim, a noção de "coalizão" está relacionada a união de dois elementos: o sistema político presidencialista e a existência de coalizão partidária, de forma que os partidos se juntam com o objetivo de formar um consórcio de apoio para sustentar o poder do Chefe de governo.

Nesse sentido, afirma Sérgio Abranches:

O Presidencialismo de Coalizão designa a realidade de um país presidencialista em que a fragmentação do poder parlamentar entre vários partidos obriga o Executivo a uma prática que costuma ser mais associada ao parlamentarismo, onde o presidente da República, mesmo que eleito diretamente, torna-se refém do Congresso. (ABRANCHES, 1988, p. 22).

Analisando essa estratégia, pode-se concluir que, quanto maior o número de envolvidos neste ajuste, maior também e a diversidade ideológica presente, e consequentemente, a heterogeneidade de opiniões, o que torna essa tática de coalizão bastante instável e arriscada. 
No que tange a esse risco de conflito, Abranches explica as fases do referido processo:

\begin{abstract}
A formação de coalizão envolve três momentos típicos. Primeiro, a constituição da aliança eleitoral, que requer negociação em torno de diretivas programáticas mínimas, usualmente amplas e pouco específicas, e de princípios a serem obedecidos na formação do governo, após a vitória eleitoral. Segundo, a constituição do governo, no qual predomina a disputa por cargos e compromissos relativos a um programa mínimo de governo, ainda bastante genérico. Finalmente, a transformação da aliança em coalizão efetivamente governante, quando emerge, com toda força, o problema da formulação da agenda real de políticas, positiva e substantiva, e das condições de sua implementação.

É o trânsito entre o segundo e o terceiro momentos que está no caminho crítico da consolidação da coalizão e que determina as condições fundamentais da sua continuidade. A formação do governo, a elaboração de seu programa de ação e do calendário negociado de eventos têm impacto direto sobre a estabilidade futura. Numa estrutura multipartidária, marcada pelo fracionamento, o sucesso das negociações, na direção de um acordo explícito que compatibilize as divergências e potencialize os pontos de consenso, é decisivo para capacitar o sistema político e atender ou conter legitimamente demandas políticas sociais e econômicas competitivas e a formular um programa coerente e efetivo. (ABRANCHES, 1988, p 27-28).
\end{abstract}

Nesta esteira, diante de toda a problemática exposta, pode-se afirmar que a tripartição do poder, foi fundamental para o surgimento do presidencialismo. Entretanto, no Brasil, o Chefe do Executivo passou a avançar sobre as competências do Poder Legislativo, agregando, como por exemplo, a atividade de produção de lei, quando na verdade, deveria ser responsável apenas pela execução destas.

Entre os diversos motivos que contribuíram para a ascensão desse cenário, podemos citar o surgimento do Estado Social, que exigiu uma interferência mais ampla do governo nas questões sociais e econômicas. Contudo, pode-se perceber que a invasão de competências entre os poderes, passou não só a causar alguns conflitos, mas principalmente a comprometer a eficiência e funcionalidade dos poderes, mais especificamente do Poder Judiciário.

Chegamos aqui ao clímax da questão, pois o problema maior do presidencialismo brasileiro não é estritamente o desequilíbrio evidente entre os órgãos fundamentais do Estado e entre seus Poderes em si, mas sim, a consequência desse desequilíbrio que é a ausência de mecanismo de controle do chefe do Poder Executivo, e a fragilidade do Poder Judiciário.

No Brasil, o Poder Executivo além de suas atribuições comuns, tem o controle sobre a produção Legislativa, não sofre a fiscalização adequada do Legislativo e ainda, dificilmente será responsabilizado por seus atos, uma vez que o mecanismo adotado no país (crime de responsabilidade política), depende de uma grande movimentação política da sociedade e das instituições públicas, o que é dificultado pela excessiva hegemonia mantida pelo presidente.

Todo esse cenário gera uma notória fragilidade democrática, uma vez que todo o sistema está dependente da pessoa que exerce o papel de Chefe do Poder Executivo, ocasionando grande dificuldade de controle político e até mesmo jurídico do Presidente da República. 


\section{CRIME DE RESPONSABILIDADE POLÍTICA}

O crime de responsabilidade política trata-se de infrações político-administrativas cometidas no desempenho da função pública. Diferentemente do crime comum, o crime de responsabilidade, apesar de nomeado como crime, possui conteúdo inteiramente político, e obviamente sanções basicamente políticas.

O conceito de crime de responsabilidade sofreu forte influência do modelo norte-americano, e teve sua primeira previsão na Constituição de 1891. Atualmente encontra-se regulamentado no Art. 85 da Constituição Federal de 1988, que prevê:

Art. 85. São crimes de responsabilidade os atos do Presidente da República que atentem contra a Constituição Federal e, especialmente, contra:

I - a existência da União;

II - o livre exercício do Poder Legislativo, do Poder Judiciário, do Ministério Público e dos Poderes constitucionais das unidades da Federação;

III - o exercício dos direitos políticos, individuais e sociais;

IV - a segurança interna do País;

$\mathrm{V}$ - a probidade na administração;

VI - a lei orçamentária;

VII - o cumprimento das leis e das decisões judiciais.

Parágrafo único. Esses crimes serão definidos em lei especial, que estabelecerá as normas do processo e julgamento. (grifo nosso).

Como descrito no Parágrafo Único do art. 85 da CF/88, os crimes de responsabilidade serão definidos em lei especial, assim como as normas de processo e julgamento. Desta forma, a referida lei especial que trata sobre o tema é a lei 1079/50 (crime de responsabilidade cometido por presidente da República), da Constituição Federal de 1988.

LEI № 1.079, DE 10 DE ABRIL DE 1950

\section{PARTE PRIMEIRA}

Do Presidente da República e Ministros de Estado

Art. 1 São crimes de responsabilidade os que esta lei especifica.

Art. $2^{\circ}$ Os crimes definidos nesta lei, ainda quando simplesmente tentados, são passíveis da pena de perda do cargo, com inabilitação, até cinco anos, para o exercício de qualquer função pública, imposta pelo Senado Federal nos processos contra o Presidente da República ou Ministros de Estado, contra os Ministros do Supremo Tribunal Federal ou contra o Procurador Geral da República.

Art. 3ำ A imposição da pena referida no artigo anterior não exclui o processo e julgamento do acusado por crime comum, na justiça ordinária, nos termos das leis de processo penal.

Art. 4 São crimes de responsabilidade os atos do Presidente da República que atentarem contra a Constituição Federal, e, especialmente, contra:

I - A existência da União:

II - O livre exercício do Poder Legislativo, do Poder Judiciário e dos poderes constitucionais dos Estados;

III - O exercício dos direitos políticos, individuais e sociais;

IV - A segurança interna do país;

$\mathrm{V}$ - A probidade na administração; 


$$
\begin{aligned}
& \text { VI - A lei orçamentária; } \\
& \text { VII - A guarda e o legal emprego dos dinheiros públicos; } \\
& \text { VIII - O cumprimento das decisões judiciárias (Constituição, artigo 89). }
\end{aligned}
$$

É importante constar que, a supracitada lei, em seus capítulos, apresenta-se taxativamente no que tange a definição de crime de responsabilidade cometido pelo Presidente da República.

Sobre o tema, define o jurista José Cretella Júnior, em seu livro "O impeachment no direito brasileiro":

$$
\begin{aligned}
& \text { [...] não há definição quanto ao crime de responsabilidade, mas uma enumeração } \\
& \text { taxativa do que deve ser o crime de responsabilidade do Presidente da República. } \\
& \text { (CRETELLA, 1992, p. 38). }
\end{aligned}
$$

Ademais, qualquer cidadão é parte legítima para oferecer acusação contra o Presidente da República à Câmara dos Deputados pela prática de qualquer ato definido como crime de responsabilidade. Contudo, a denúncia só poderá ser recebida enquanto o denunciado não tiver deixado o cargo definitivamente. Recebida a referida acusação pela Câmara dos Deputados, o julgamento ocorre mediante processo de impeachment podendo resultar, caso confirme-se a existência de crime de responsabilidade, na perda do cargo, ou, eventualmente no impedimento para exercício da função pública e inelegibilidade para cargo público. ( $\mathrm{O}$ referido processo de julgamento será detalhado nos próximos tópicos).

Ainda nesse contexto, conforme prevê a Súmula Vinculante 465 , é de competência privativa da União o estabelecimento das normas de processo e julgamento, assim como a definição do crime de responsabilidade. Assim, o Presidente da República será processado e julgado por crimes de responsabilidade, conforme prevê a Constituição Federal, perante o Senado Federal (art 52, I, da CF/88), depois de admitida a acusação pela Câmara dos Deputados (art $51, \mathrm{I}, \mathrm{CF} / 88)$.

De uma forma geral, pode-se afirmar que o crime de responsabilidade é um crime meramente político, e, desta forma, julgado por instâncias políticas e agentes políticos, sendo imputado ao Presidente apenas sansões políticas que não devem ser confundidas com as sanções penais, pois o objetivo central é apenas estabelecer parâmetros jurídicos e garantias para o julgamento político, sem, no entanto, se igualar ao processo judicial.

\section{PROCESSO DE IMPEACHMENT}

O processo de impeachment, também conhecido como processo de impedimento ou destituição é o meio utilizado para processar e julgar os crimes de responsabilidade. Esse processo encontra-se previsto na lei 1079/1950, assim como no art 85 e 86 da Constituição Federal de 1988.

5 Súmula Vinculante ํㅡ 46: A definição dos crimes de responsabilidade e o estabelecimento das respectivas normas de processo e julgamento são de competência legislativa privativa da União. 
Assim sendo, trata-se de um processo bifásico, ou seja, dividido em duas fases, em que o início se dá com a denúncia do Presidente da República perante a Câmara dos deputados. Vale ressaltar que, está denúncia pode ser realizada por qualquer cidadão, conforme Art. 14 da lei 1079/506.

Além disso, a denúncia só poderá ser recebida enquanto o denunciado não tiver deixado o cargo, e também, deve ser assinada pelo denunciante com firma reconhecida acompanhado com os documentos que a comprovem, ou com declaração de impossibilidade de apresentálos, com a indicação do local onde possam ser encontrados. E, nos crimes de que haja prova testemunhal, a denúncia deverá conter um rol de, no mínimo, 5 testemunhas (art 15 e 16 da lei 1079/50).

A primeira fase do processo acontece no tribunal de pronúncia, composto pela Câmara dos Deputados, onde ocorre o juízo de admissibilidade do processo. Ou seja, após recebida a denúncia, esta será despachada a uma comissão especial eleita (composta pelos representantes dos partidos), para, em 48 horas, opinar sobre esta, além de eleger seu presidente e relator, para em 10 dias, emitir um parecer sobre se a referida denúncia, se esta deve ou não ser objeto de deliberação (art 19 e 20 da lei 1079/50).

Emitido o parecer pela Câmara, 5 representantes de cada partido poderão falar, assim como o relator da comissão especial terá o direito de responder cada um deles, conforme prevê o art. 21 da lei 1079/50. Desta forma, encerrada a discursão do parecer, será realizada a votação nominal, e, caso não seja a denúncia considerada objeto de deliberação, esta será arquivada. Porém, em caso positivo, será remetida uma cópia ao denunciado que terá o prazo de 20 dias para, caso queira, contestá-la. Findo esse prazo, a após realizadas todas as diligências necessárias, a comissão especial, no prazo de 10 dias, irá emitir um parecer sobre a procedência ou improcedência da denúncia (art 22 e 23 da lei 1079/50).

Julgada procedente a denúncia, esta será enviada para o Senado Federal, assim como para o acusado, que poderá por si só, ou através de seus advogados apresentar sua defesa (art. 25 da Lei 1079/50)7. Nesta etapa encerra-se a primeira fase do processo, dando, seguidamente, andamento a fase posterior. A segunda fase é realizada pelo tribunal de julgamento, composto pelo Senado Federal, que irá realizar o julgamento do processo.

Ocorre aqui, devido a ADPF 378 apresentada pelo partido PC do $\mathrm{B}$, a alteração em alguns dispositivos relacionados ao procedimento desse processo, um deles é a aplicação de um novo juízo de admissibilidade pelo Senado, que será, melhor esclarecido no próximo tópico.

Importante citar que, a sessão de julgamento que ocorre no Senado Federal é presidida pelo presidente do Supremo Tribunal Federal.

Desta forma, serão realizadas todas as diligências necessárias, como discursões orais, recolhimento de provas entre outros. Finalizada esta etapa, ocorrerá o julgamento. Se o resultado for absolutório, desde de logo produzirá todos os efeitos a favor do acusado. Porém,

6 Art. 14. É permitido a qualquer cidadão denunciar o Presidente da República ou Ministro de Estado, por crime de responsabilidade, perante a Câmara dos Deputados.

7 Art. 29. Realizar-se-á a seguir o debate verbal entre a comissão acusadora e o acusado ou os seus advogados pelo prazo que o Presidente fixar e que não poderá exceder de duas horas. 
se condenatório, o condenado, além de perder o cargo, ficará inabilitado de exercer qualquer função pública pelo período de 8 anos (art 31, 32 e 33 da Lei 1079/50)8.

Ainda sobre o tema, é imprescindível esclarecer que, é necessário para que o processo possa prosseguir, tanto na Câmara dos Deputados, que realiza o juízo de admissibilidade, como no Senado Federal, que é responsável pelo julgamento do processo, o quórum de aprovação é de 2/3, de acordo com o art 86 da Constituição federal de 1988. O que significa, na Câmara (tribunal de pronúncia) 342 votos. E, no Senado Federal (tribunal de julgamento), 54 votos dos 81 Senadores.

Mediante todo o procedimento descrito, percebe-se que se trata de um processo bastante complexo, que, para sua ocorrência, necessita, não somente de uma manifestação política social como também uma forte movimentação das instituições públicas, desta forma, para que haja uma votação favorável a condenação do Presidente, é indiscutivelmente necessário que, as alianças existentes entre o Poder Executivo e Legislativo estejam comprometidas.

Um exemplo desse cenário é o processo de Impeachment contra a Presidente Dilma Rousseff, em que sua base aliada era formada por 304 deputados e 51 senadores, restando evidente portanto que, se a coalizão desses poderes estivesse firme e sólida, seria improvável a hipótese de aprovação da denúncia para julgamento do processo de impedimento.

\subsection{ADPF 378}

A Arguição de Descumprimento de Preceito Fundamental impetrada pelo partido PC do $\mathrm{B}$, a ADPF 378, é uma ação constitucional que buscou analisar a legitimidade constitucional do processo de Impeachment, previsto na lei 1079/1950.

A respeito da votação da contada ADPF, a corrente majoritária seguiu o voto do Ministro Luís Roberto Barroso, que foi contrário ao voto do relator da ação, o Ministro Edson Fachin, que em seu voto, rejeitava a necessidade de defesa prévia do Presidente da República, a vedação ao voto secreto para a formação da Comissão especial e a possibilidade de o Senador rejeitar a instauração do processo.

De forma bem sucinta, entre os temas colocados em pauta, foi definido pelo Supremo Tribunal Federal, após o julgamento, que a Câmara dos Deputados apenas dá a autorização para a abertura do processo de Impeachment, cabendo ao Senado Federal fazer o juízo inicial de instalação ou não do procedimento, quando a votação se dará por maioria simples, ou seja, mesmo após a admissão da denúncia pela Câmara dos Deputados, o Senado Federal pode optar em prosseguir ou não com o processo. Outro ponto foi que a votação para escolha da comissão especial na Câmara deve ser aberta, sendo ilegítimas as candidaturas avulsas de

\footnotetext{
8 Art. 31. Encerrada a discussão o Presidente do Supremo Tribunal Federal fará relatório resumido da denúncia e das provas da acusação e da defesa e submeterá a votação nominal dos senadores o julgamento.

Art. 32. Se o julgamento for absolutório produzirá desde logo, todos os efeitos a favor do acusado.

Art. 33. No caso de condenação, o Senado por iniciativa do presidente fixará o prazo de inabilitação do condenado para o exercício de qualquer função pública; e no caso de haver crime comum deliberará ainda sobre se o Presidente o deverá submeter à justiça ordinária, independentemente da ação de qualquer interessado. 9 DEN 1/2016 - Hélio Pereira Bicudo, Janaína Conceição Paschoal, Miguel Reale Júnior. Disponível em: <http://www25.senado.leg.br/web/atividade/materias/-/materia/125567> - Acessado em 20/10/2016.
} 
Deputados para a sua composição. Além do afastamento do Presidente da República ocorrer apenas se o Senado abrir o processo.

Destarte, pode-se deduzir que após a Arguição de Descumprimento de Preceito Fundamental № 378, houve a um "novo" juízo de admissibilidade pela Senado, em que pese que o STF entendeu que se o Senado possui competência para processar e julgar, este também seria competente para avaliar todos os requisitos necessários para a instauração do processo, e assim sendo, somente depois do juízo de admissibilidade do Senado, poderia então, haver a suspensão do chefe do Poder Executivo.

Mas, sabendo-se que o papel do Supremo Tribunal Federal no processo de impedimento seria somente de presidir a sessão de julgamento, não estaria então o Poder Judiciário, após decidir por algumas alterações no processo de impeachment, adentrado nas funções designadas ao Poder Legislativo?

Vale lembrar que trata-se de um processo político, que enseja em sanções na esfera política e que, de fato, é de competência do Poder Legislativo. Contudo, também deve-se levar em consideração que todo esse procedimento, ocorre nos moldes de um processo tipicamente jurídico. Mais uma vez, é visível a existência da confusão entre as esferas de Poder, na medida em que ocorre, nesse caso, o desalinho entre o âmbito jurídico e político.

\section{CONCLUSÃo}

Desde o surgimento do presidencialismo no Brasil há existência de um sistema tripartite fragilizado. Vez que, no país, a saída encontrada para "monopolizar" o poder na esfera Executiva foi a união oculta de dois poderes (Executivo e Legislativo) o que comprometeu significativamente a autonomia de cada poder, e consequentemente o sistema de freios e contrapesos, baseada na Teoria de Montesquieu. E assim, por conseguinte, o desandar de toda a harmonia, como a eficiência da Esfera Judiciária.

Nesta esteira, a medida que o Poder Judiciário encontrou para impor sua importância, foi, de certa forma, o abuso de suas prerrogativas, vez que, como por exemplo no processo de impeachment, atuou, no caso da Presidente Dilma Rousseff, não só como árbitro, mas muitas vezes, coordenou e liderou o andamento do processo de julgamento, além de definir algumas alterações no procedimento, através da ADPF 378. Vale lembrar que se trata de um processo político-administrativo de conteúdo inteiramente político, onde as sanções decorrentes desse processo são, ou deveriam ser, basicamente políticas.

O fato de se tratar de um sistema falho, compromete não só as funções absolvidas por outros poderes, mas o funcionamento do sistema como um todo, posto que a separação tripartite utiliza como ideia central não apenas a separação de funções entre os poderes, mas principalmente o uso deles como seus próprios fiscalizadores. Ademais, se um único órgão do poder fosse capaz de suprir todas essas atividades e realizá-las de forma justa e organizada, não se faria necessária então essa divisão. 
O problema é que se desses órgãos se apresentam de forma superior, isso compromete todo o sistema, implantando o desequilíbrio e oscilação dos poderes e consequentemente interferindo diretamente no bom funcionamento da democracia. Pois, se existe uma esfera de poder que possui superioridade as demais, esta, tem domínio sobre as outras esferas, e acaba por abafar ou até mesmo impossibilitar atividades como sua fiscalização.

O processo de impeachment é um retrato claro desse cenário, uma vez que deveria ser uma ferramenta de simples controle utilizado na fiscalização do chefe do Poder Executivo, tornouse, devido a esse desequilíbrio, símbolo de desmoronamento de alianças e acordos entre as esferas. E, um procedimento simplesmente político que respeitava apenas os moldes jurídicos, passou a ser um o foco de todo o sistema judiciário.

Infelizmente, uma explicita inversão de competências e invasão de esferas, o âmbito político constantemente interferindo no judiciário, o poder legislativo deixando de exercer certas condutas para manter o conchavo com o Poder Executivo, e o judiciário exorbitando suas atuações. Um quadro alarmante para um sistema complexo, inventivo na teoria, mas que na prática é corrompido.

\section{REFERÊNCIAS}

ABRANCHES, Sérgio Henrique Hudson de. Presidencialismo de Coalizão: o dilema institucional brasileiro. Revista de Ciências Sociais, Rio de Janeiro. v. 31, n. 1, p. 5-34, 1988.

LENZA, Pedro. Direito Constitucional esquematizado. 20aㅡ ed. São Paulo: Ed. Saraiva, 2016.

MENDES, Gilmar Ferreira; BRANCO, Paulo Gustavo Gonet. Curso de Direito Constitucional. 9ae ed. São Paulo: Saraiva, 2014.

OLIVEIRA, Erival da Silva. Direito constitucional. 14 $4^{\mathrm{a}}$ ed. São Paulo: Revista dos Tribunais, 2016.

RAMIRO, Caio Henrique Lopes. Jornal da Fundação. Agosto de 2013. Constituição e política: Apontamentos sobre Carl Schmitt. Disponível em: <http://www.univem.edu.br/jornal/materia.php?id=367>. Acessado em 13 de Jul. 2016.

SCHMITT, Carl. O Guardião da Constituição. Belo horizonte: Del Rey, 2007.

SOARES, Marcos Antônio Striquer. Características do Presidencialismo no Brasil e Fragilidade Democrática: Dificuldades de Controle do Presidente da República no Brasil. Semina: Ciências Sociais e Humanas, Londrina, v. 24, p.1-24, 2003.

STF. STF reafirma rito aplicado ao processo de impeachment de Fernando Collor. Notícias STF. Brasília. 17. Dezembro. 2015. Disponível em:

<http://www.stf.jus.br/portal/cms/verNoticiaDetalhe.asp?idConteudo=306614 >. Acessado em 01 de Set. 2016.

STF. STF rejeita recurso contra decisão sobre rito de impeachment. Notícias do STF. Brasília. 16. Março. 2016. Disponível em:

$<$ http://www.stf.jus.br/portal/cms/verNoticiaDetalhe.asp?idConteudo=312246>. Acessado em 01 de Set. 2016. 